\title{
Rota de Integração Latino-Americana (RILA) para o desenvolvimento turístico
}

\author{
Route of Latin American Integration (RILA) for tourism development \\ Ruta de Integración Latinoamericana (RILA) para el desarrollo turístico
}

\author{
Thiago Andrade Asato ${ }^{1}$ \\ Michel Constantino ${ }^{1}$ \\ Arlinda Cantero Dorsa ${ }^{1}$ \\ Milton Augusto Pasquotto Mariani²
}

Recebido em 15/05/2018; revisado e aprovado em 12/09/2018; aceito em 18/06/2019

DOI: http://dx.doi.org/10.20435/inter.v20iespecial.1994

\begin{abstract}
Resumo: Este artigo trata sobre a Rota de Integração Latino-Americana (RILA) ou Rota Bioceânica, fomentando como tal rota pode contribuir para o desenvolvimento local de Mato Grosso do Sul e, consequentemente, dos países que permeiam o trajeto completo do corredor, no olhar voltado ao desenvolvimento turístico. A pesquisa pautou-se de entrevistas semiestruturadas direcionadas aos gestores que participaram da caravana de teste da II Rota de Integração Latino-Americano (denominada Rila), realizada em agosto de 2017.
\end{abstract}

Palavras-chave: Rota Bioceânica; logística; turismo; desenvolvimento local.

Abstract: This article deals with the Latin American Integration Route (RILA) or Bioceanic Route, promoting how such route can contribute to the local development of Mato Grosso do Sul and, consequently, of the countries that permeate the complete path of the corridor, development. The research was based on semistructured interviews directed to the managers who participated in the test caravan of the II Latin American Integration Route (called Rila), held in August 2017.

Keywords: Bioceânica Route; logistics; tourism; local development.

Resumen: Este artículo trata sobre la Ruta de Integración Latinoamericana (RILA) o Ruta Bioceánica, fomentando como tal ruta puede contribuir al desarrollo local de Mato Grosso del Sur y, consecuentemente, de los países que permean el trayecto completo del corredor, en la mirada volcada al desarrollo turístico. La encuesta se basó en entrevistas semiestructuradas dirigidas a los gestores que participaron en la caravana de prueba de la II Ruta de Integración Latinoamericana (denominada Rila), realizada en agosto de 2017.

Palabras clave: Ruta Bioceánica; logística; turismo; desarrollo local.

\section{INTRODUÇÃO}

O Corredor Bioceânico é tema de discussão no Brasil e, especificamente em Mato Grosso do Sul, desde meados de 2006 (mesmo que em menor escala), porém só em 2017 houve uma maturação a respeito do tema e, mais especificamente nesse ofício, a ênfase volta-se às potencialidades da efetivação do Corredor para Mato Grosso do Sul. A sua operacionalização é movida, inicialmente, por um viés para a atividade de logística e transporte como alternativa para escoar grãos e fomentar uma distribuição mais acelerada da produção e, em segundo plano, pelo turismo.

Caso venha a se concretizar, o Corredor tem como vetor ligar Mato Grosso do Sul, na fronteira de Porto Murtinho com a República do Paraguai, a partir de uma nova ponte (o trecho é feito há mais de duas décadas via balsa), passando pelo Paraguai e pela Argentina até chegar ao Chile. A sua construção poderá incrementar a economia sul-mato-grossense, em relação às empresas de logística e para o fortalecimento de novas (e velhas) potencialidades turísticas.

\footnotetext{
${ }^{1}$ Universidade Católica Dom Bosco (UCDB), Campo Grande, Mato Grosso do Sul, Brasil.

${ }^{2}$ Universidade Federal de Mato Grosso do Sul (UFMS), Campo Grande, Mato Grosso do Sul, Brasil.
} 
Pretende-se, com este trabalho, tecer considerações iniciais acerca do Corredor Bioceânico e da possível rota turística dos países pelos quais passará. Para tanto, estabeleceu-se o seguinte roteiro de pesquisa: 1) o mapeamento dos municípios e das cidades que ladeiam o Corredor, 2) os principais atrativos turísticos locais e 3) as potencialidades turísticas a serem diagnosticadas.

A metodologia utilizada é a pesquisa qualitativa, bibliográfica e documental, com entrevistas semiestruturadas em material fornecido pela Associação Comercial e Industrial de Campo Grande (ACICG-MS), entidade responsável por conduzir representantes comerciais em uma caravana de reconhecimento do trajeto como um todo. A pesquisa bibliográfica norteou-se, inicialmente, a partir de periódicos encontrados na plataforma Capes por meio das palavras chaves "Rota Bioceânica" e "Corredor Bioceânico".

Ademais, procurou-se, com tal iniciativa, discorrer sobre a importância da Rota para o desenvolvimento local e para o fortalecimento da integração entre os países pertencentes ao Corredor Bioceânico.

\section{O CORREDOR BIOCEÂNICO: O URBANO E A INFRAESTRUTURA LOGÍSTICA}

Tema relativamente novo em Mato Grosso do Sul, a tônica do Corredor Bioceânico tem apenas correlacionadas no meio acadêmico uma monografia e uma dissertação de mestrado no estado de Mato Grosso do Sul. É preciso, portanto, que, simultaneamente à intensificação das ações voltadas ao Corredor, sejam realizadas pesquisas mais aprofundadas que venham atender às interfaces históricas, culturais, econômicas, sociais e turísticas.

O Corredor Rodoviário Bioceânico, como um dos elementos de suporte da Rota de Integração Latino-Americana (Rila), terá cerca de 2,2 mil quilômetros de percurso entre Campo Grande e os portos do norte do Chile. O início dos trabalhos relativos à abertura da Rota de Integração intensificou-se a partir da segunda expedição realizada por empresários do Estado e do poder público, denominada Rila, no período de 25 de agosto a 2 de setembro de 2017. A primeira expedição foi feita em meados de 2013. Houve ainda outras três viagens isoladas por caminhos que pudessem viabilizar (e encurtar) o percurso, como um trecho pela Bolívia, porém a falta de infraestrutura nas estradas daquele país e motivações históricas, inclusive de guerra entre o Chile e a Bolívia (1879-1883), que bloqueou o acesso ao mar à Bolívia, impossibilitou a viabilização da Rota de Integração por aquele país. Para ilustrar os municípios e os distrito-sedes que ladeiam o trajeto, conforme primeiro objetivo ocorre mapeá-los. Dessa forma, em conformidade com a figura 1, norteada por setas considera-se a saída e o retorno a cidade de Campo Grande.

Ao mapear o roteiro por completo, percebe-se a passagem por 12 localidades, ao longo de todo o Corredor Bioceânico, que é o eixo integrador da Rota de Integração Latino-Americana. O primeiro tratado internacional já firmado diz respeito à construção de uma ponte no Brasil, ligando Porto Murtinho (2) a Carmelo Peralta (3), no Paraguai, ilustrado na forma de numeração conforme mapa (Figura 1). Esta obra deverá ser financiada pelos dois países. Estima-se que a ponte terá 500 metros de comprimento. 
Figura 1 - Mapa da Rota de Integração Latino-Americana (Rila)

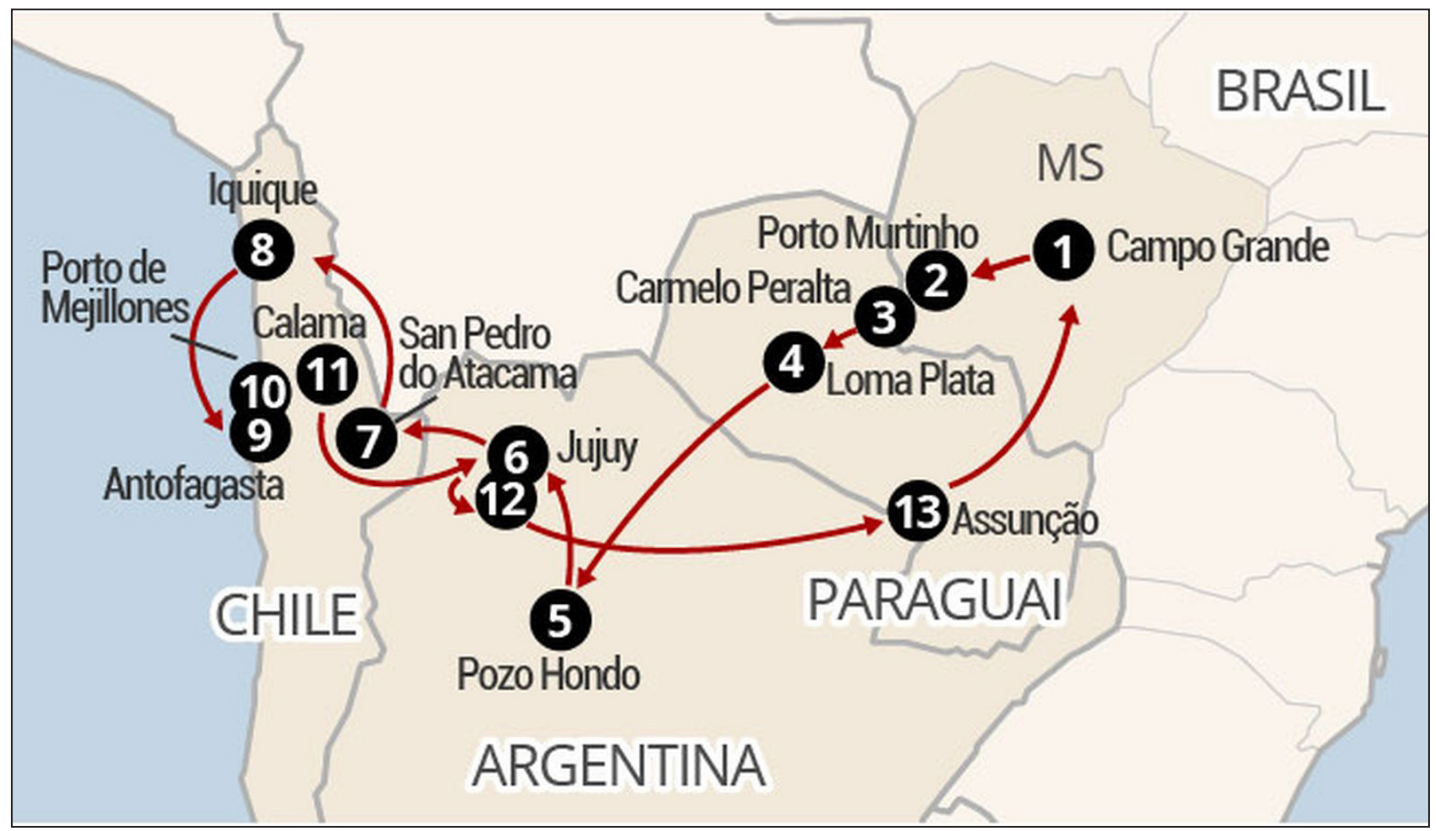

Fonte: VIEGAS (2017).

Com o rompimento dessa barreira geográfica, além da redução de rota marítima para a exportação de produtos para outros continentes, avaliam-se, pelo lado paraguaio, trâmites que facilitem a pavimentação de rodovias (cerca de $500 \mathrm{~km}$ ), e outros $24 \mathrm{~km}$ na Argentina, no intuito de facilitar a logística, e, em segunda ordem, potencializar o turismo ao longo do Corredor. No trecho paraguaio, que é o mais delicado, já existe um processo de licitação em andamento, para, em seguida, iniciar o projeto de pavimentação.

Segundo o Secretário Estadual de Meio Ambiente, Desenvolvimento Econômico, Produção e Agricultura Familiar de Mato Grosso do Sul MS (Semagro), a viabilização desse Corredor possibilitará ao turista visitar o Pantanal e a cidade de Bonito, seguir para o Chaco Paraguaio, conhecer a região de Salta na Argentina, finalizando o roteiro no Deserto do Atacama, no Chile. A ressalva é o fato de que é necessário desenvolver primeiramente a Rota de Integração, para que todos os países sejam beneficiados.

Alguns pressupostos para a facilitação do desenvolvimento de infraestrutura do trajeto e da desburocratização resumem-se em i) simplificação dos processos alfandegários nas divisas entre os países; ii) pavimentação de cerca de 530 km em trechos de estrada na Argentina e Paraguai; iii) promoção de meios de sinalização turística; iv) capacitação de pessoas com relação aos atrativos da Rota de Integração, desde os que já existem até outros que possam ser viabilizados com a sua abertura, assim como v) a integração cultural que envolve o Corredor Rodoviário, por estabelecer trajeto e relações entre quatro países da América do Sul.

Uma problemática inicial que ocorre é na passagem da fronteira de Porto Murtinho, no Brasil, para Carmelo Peralta, no Paraguai. Esta atualmente é realizada por uma pequena balsa e, dependendo do modelo do veículo e do peso, dá-se passagem apenas para quatro veículos por vez. Numa eventual viagem de grupo, dependendo do número de pessoas, tal trecho praticamente inviabilizaria esse tipo de viagem. Daí a necessidade premente da ponte, como ponto de partida para a implantação do Corredor Rodoviário Bioceânico. Na atual conjuntura, a logística para a 
passagem de ônibus inviabiliza o turismo para grupos maiores e de caminhões, dificultando o transporte de mercadorias em maior escala.

Estima-se, a partir da construção da ponte, segundo o empresário e presidente do Sindicado das Empresas de Transporte e Logística de Mato Grosso do Sul (SETLOG), um dos idealizadores da Rila, uma redução de cerca de até $12 \%$ do preço do frete, com ressalvas de que a produção no Estado pode aumentar e gerar mais divisas entre os países que fazem parte do Corredor Rodoviário.

Ao resumir os resultados da última caravana empresarial de estudo de viabilidade do Corredor, Claudio Cavol, Presidente do Sindicato das Empresas de Transporte Rodoviário de Cargas e Logística/MS, menciona aspectos positivos que vão além da vontade política dos quatro países:

Foi percebido ao longo do caminho as manifestações de apoio da população das cidades por onde o corredor vai passar, demonstrando a esperança de que junto com a rota chegue também desenvolvimento, emprego e renda. Isso foi o mais marcante de toda a viagem.

Segundo Ezequiel Resende, Coordenador da Unidade de Economia, Estudos e Pesquisas da Federação das Indústrias do Mato Grosso do Sul (Fiems), além do ganho de tempo e redução de custos com transporte e logística, há novas possibilidades de negócios no Corredor Rodoviário, pois "será necessário construir todo o aparato de suporte, como postos de combustivel, serviços relacionados à manutenção e reparação de veículos, alimentação, hospedagem".

O projeto conta ainda com a aprovação de comunidades menonitas, imigrantes alemães cristãos, que povoam as margens do Corredor Rodoviário em trechos paraguaio e argentino. A característica cultural intrínseca a cada comunidade que engloba o contexto do Corredor é mais um dos pressupostos a serem explorados pelo turismo. Além de se tornar mais um acesso ao Oceano Pacífico, ocorre mencionar o fomento à união dos povos integrantes do Corredor Bioceânico. Daí o sentido da Rota de Integração Latino-Americana.

O trecho chileno é considerado o mais preparado do Corredor, por conta da infraestrutura das rodovias e pela alta capacidade de carga dos portos de lquique, Mejillones e Antofagasta, sem a necessidade de reformas ou maiores reparos. Ocorre apenas uma retificação em relação à aduana (órgão público que fiscaliza entrada e saída de mercadorias) na fronteira argentina. Tal órgão abre às 8 horas e fecha às 18 horas por questões de segurança, frio intenso, ausência de pontos de apoio e sinal de telefonia, que dificulta as chamadas em casos de emergência.

O que merece ser enfatizado neste contexto, é o turismo de contemplação presente em grande parte do Corredor, com destaque para o deserto de sal de Salinas Grandes, próximo de San Salvador de Jujuy, na Argentina, numa extensão de 12 mil hectares, além de trecho da Cordilheira dos Andes e do Deserto de Atacama, no trecho Chileno.

\section{POTENCIALIDADES TURÍSTICAS E DESENVOLVIMENTO LOCAL}

A Rota de Integração Latino-Americana, com a implantação do Corredor Rodoviário, possibilitará ligar o Oceano Atlântico ao Pacífico. Sua viabilização começará com a construção da ponte entre Porto Murtinho (Brasil) e Carmelo Peralta (Paraguai). No fim, o Corredor Rodoviário irá agilizar as exportações brasileiras para os países asiáticos e a costa oeste americana pelo Oceano Pacífico. A partir dessa viabilização logística, dá-se a potencialidade de alavancar o turismo em toda a região. O Corredor Rodoviário é, portanto, um dos elementos importantes da Rota de Integração. 
Como sumarizam Taussig, Hoeyer e Helmreich (2013), o potencial é um conceito orientador nas práticas médicas, objeto de políticas de nomeação e enquadramento (naming e framing). Segundo Taussig, Hoeyer e Helmreich (2013, p. S4), são três os significados de potencialidade:

The first denotes a hidden force determined to manifest itself - something that with or without intervention has its future built into it. The second refers to genuine plasticity the capacity to transmute into something completely different. The third suggests a latent possibility imagined as open to choice, a quality perceived as available to human modification and direction trough which people can work to propel and object or subject to become something other than it is.

Assim, interessa ainda abordar o potencial do turismo da região por meio de reportagens da mídia jornalística e da academia dos países participantes do Corredor, considerados como interlocutores deste trabalho, vista a ocorrência de pouquíssimos trabalhos científicos sobre o tema. Por exemplo, citando como fonte jornalística, o G1, no Brasil, pode-se observar um total de 24 reportagens sobre o Corredor Bioceânico, em 2017. A mídia argentina coloca em destaque a exportação do vinho entre os países coparceiros da Rota de Integração Latino-Americana, fato que será ponderado neste trabalho.

O lado paraguaio poderá se beneficiar de forma dupla. Primeiro, com a construção da ponte em Carmelo Peralta, divisa com Porto Murtinho, trazendo maior desenvolvimento na cidade fronteiriça com o Brasil e todo o aporte duplo binacional, na construção eventual da ponte, que proporcionará mais geração de emprego e de divisas, além da facilitação do turismo rodoviário rumo a San Pedro do Atacama, destino principal do Corredor Rodoviário, no Chile.

Em segundo plano, dá-se também o desenvolvimento de um segundo segmento da Rota de Integração, nesse caso fundamentalmente econômico e comercial, o chamado corredor em massa (em espanhol chamado de "corredor granelero"), que se trata de um acordo desenhado entre o governo paraguaio e o do Brasil. O acordo gira em torno da permissão de tráfego de caminhões bitrens por todo território paraguaio, possibilitando maior competitividade ao setor de transportes nesse país. Segundo reportagem do jornal paraguaio La Nación (2018), tal determinação remonta o transporte de um milhão de toneladas de grãos, que é $10 \%$ de tudo o que o Paraguai já produz. Ou seja, é uma quantidade adicional do que foi produzido até fim de 2017, e que os caminhões paraguaios já transportam.

Em relação às universidades, os projetos de projetos de pesquisa celebrados em agosto de 2017, com visão de futuro para a integração entre universidades dos países do Corredor, conforme reportagem do G1 (VIEGAS, 2017b), destaca-se que

A equipe da Universidade Estadual de Mato Grosso do Sul (UEMS) que participou da rota, com o reitor, Fábio Edir, com o assessor de relações internacionais Ruberval Maciel e o coordenador do Grupo de Estudos em Fronteira, Turismo e Território, Roberto Paixão, formalizou parcerias com duas instituições da região, a Universidade Nacional de Jujuy e Universidade Nacional de Salta.

Ademais, cabe ressaltar a descoberta de lugares ainda pouco conhecidos como atrativos de massa, mas que a partir da iniciativa de parceria entre os países, despontam como potencialidades reais de destinação turística, ao menos complementar às já conhecidas (destaque para o deserto de Atacama), como Antofagasta, no Chile, quinta maior população do país.

O turismo cultural com destaque gastronômico para a região de Salta, no norte da Argentina, cidade conhecida pela produção de vinhos, carne e feijão será beneficiada com a abertura do 
Corredor Rodoviário Bioceânico. No local são relevantes os patrimônios históricos como museus, igrejas, praças e casas no estilo europeu.

Por turismo cultural, segundo parecer de Silberberg (1995, p. 361) entende-se "visitas de pessoas de fora da comunidade receptora motivadas completamente ou em parte por interesses na oferta histórica, artística, científica, ou no estilo de vida, tradições da comunidade, religião, grupo ou instituição".

O município de Salta tem referência ainda pelos patrimônios históricos, como praças e museus, além de balneários municipais, parques, praias e o porto, dentre outros pontos de menor atratividade. Para efeito de conhecimento, a região ainda é conhecida como um dos pioneiros na criação da Saltenha, uma iguaria típica conhecida na Argentina e também na Bolívia.

No que diz respeito aos vinhos argentinos, segundo Andrés Krom (2017), a assinatura do acordo com os outros países da Rota de Integração, principalmente com o Chile, permitirá um melhor transporte de vinhos com trens para os portos chilenos. A Argentina e o Chile, aliás, além Corredor Bioceânico, discutem também outro corredor, chamado Corredor Ferroviário Binacional. Segundo Ehuletche (2017), resta um trecho de aproximadamente 300 km de via férrea, que permitirá mais transporte de carga, de forma mais sustentável. Esse corredor aumentaria o desenvolvimento da região da Patagônia, além da ligação entre Bahia Blanca, no Atlântico, e Talcahuano, no Oceano Pacífico.

Voltando ao turismo de massa, deve-se ressaltar como referência turística na Rota de Integração a cidade de San Pedro do Atacama, em pleno deserto do Atacama, cidade histórica de 1550, com cerca de três mil habitantes. Na discussão de resultados parciais, será referenciado um mapeamento das principais informações acerca do Corredor Bioceânico, no que diz respeito a destinos turísticos principais e secundários, além de considerações acerca de sinalização turística e projetos de médio e longo prazo para o desenvolvimento do mesmo Corredor.

Tendo como ponto alto o turismo, San Pedro do Atacama revela ares místicos, pela aridez e pelos meteoritos encontrados no local. A arquitetura também é intrínseca ao território, onde prédios e casas tiveram como matéria-prima o barro do deserto. Há de se mencionar, porém, que nem sempre foi assim. A característica cultural da região e o fluxo emergente de turistas tiveram algumas rupturas a partir de 2002, como alguns atentados de cunho religioso, conforme avalia Gundermann (2004, p. 222):

En un sentido esto se ve confirmado por el radical cambio de pueblo, de un oasis del desierto nortino, a destino turístico emblemático para los chilenos y para extranjeros que se dirigen a Chile. Apunta en la misma dirección el desarrollo de proyectos de inversión públicos y privados importantes en la comuna homónima que, junto con lo anterior, acarrean una avalancha de gentes moviéndose por la zona, aumentando así las posibilidades de hurtos o 'actos vandálicos'.

Tais acontecimentos acarretam reflexões sobre a necessidade de ordenamentos na região. Estes passam pelo adequado planejamento turístico, sobre o que há de concreto de elementos turísticos e o que pode ser potencial turístico a ser explorado, à medida que a Rota de Integração faça parte de um corredor turístico internacional. Pressupõe-se que, aumentando a divulgação acerca da Rota de Integração e do Corredor Bioceânico, haverá um crescimento na demanda (e na oferta) dos destinos que fazem parte desse Corredor e, com o aumento do fluxo, mais necessários serão os estudos de planejamento hoteleiro, pontos de apoio, desburocratização de processos alfandegários, padrão de atendimento ao turista, assim como a importância do intercâmbio cultural, dentre outras demandas. 
Segundo essa linha de pensamento, em médio e longo prazo, a partir das obras da ponte na ligação Brasil e Paraguai e das obras de pavimentação nos trechos que ligam Paraguai e Argentina, é grande a possibilidade de fortalecimento de divulgação da Rota de Integração para o turismo, principalmente pelos atrativos que não existem no Brasil, caso do deserto (do Atacama, no Chile), e a região da Cordilheira, que despertarão interesse dos brasileiros. Do lado contrário, certamente haverá um crescente de turistas estrangeiros desses países da Rota de Integração, com interesse nos destinos turísticos brasileiros, com evidência para Bonito e Pantanal. Ocorre ainda a ressalva para a facilitação no trâmite de logística para produtos como os vinhos chilenos e argentinos, que devem ser importados a preços inferiores, com a viabilidade do Corredor Bioceânico.

\section{DISCUSSÃO DE RESULTADOS}

A Rila pode contribuir para o incremento turístico de Mato Grosso do Sul, e, por conseguinte, das cidades adjacentes a todo o Corredor Bioceânico. Por ora trata-se de um estudo pautado inicialmente em potencialidades, enquanto alternativa de desenvolvimento turístico. Para tanto, inicialmente, sobre os atrativos turísticos nas cidades do Corredor Bioceânico, e não do que poderá vir a ser, pois se entende que há muito que se fazer até a construção da ponte entre Porto Murtinho e Carmelo Peralta. Em outras palavras, a Rota de Integração é alternativa viável que complementa o turismo de todos os países do Corredor.

Para efeito de ilustração, julgou-se oportuno dividir o Corredor Rodoviário levando em consideração as localidades de cada país, contemplando inicialmente os principais atrativos turísticos e as potencialidades acerca de incremento desses atrativos. Outros dados de turismo local, como quantidade de visitantes/ano, meio de transporte utilizado e demais considerações serão explicitados apenas de forma parcial, como complemento da tese supracitada.

Se se tomar por base a Rila, o ponto de partida no Brasil, do Corredor é Campo Grande. De acordo com o Relatório-Base (dados de 2016) da Agência Estadual de Regulação de Serviços Públicos (Agepan), na modalidade Fretamento rodoviário, Campo Grande (com 42.725 passageiros) e Bonito (23.813 passageiros) representam 52,7\% da movimentação de passageiros transportados nessa modalidade em todo o estado de Mato Grosso do Sul. Não está computada nesses dados a movimentação de passageiros na modalidade "Fretamento Contínuo", que compreende o transporte de funcionários de empresas, trabalhadores rurais, estudantes e pessoas em tratamento de saúde.

Em relação ao comportamento do turista que chega a Campo Grande no quesito "Meio de transporte utilizado", a pesquisa de Sondagem do Consumidor da FGV/Indicadores de Turismo, de 2016, aponta que 38,8\% dos turistas vêm ao Estado de avião, mesma porcentagem para automóvel (38\%), seguido de ônibus (15\%).

A partir da construção da ponte na divisa Porto Murtinho e Carmelo Peralta, abrir-se-ão novas possibilidades de rotas terrestres que contemplem não só os dois países, mas também ida e volta desde o ponto final do Corredor. No caso o Chile, seja para viagens de turismo científico (pesquisas acadêmicas), turismo cultural e ecológico (Corumbá e Bonito), aos turistas que vierem dos outros países da Rota de Integração ao Brasil e, da mesma forma, o contrário, daqueles de origem brasileira com destino principal o Deserto do Atacama, e secundários (Salta, na Argentina), por exemplo. Há que se mencionar também Assunção, no Paraguai, e Antofagasta, no Chile, como destinos indutores. 
Figura 2 - Ruta del vino (Rota do Vinho), em Salta, na Argentina

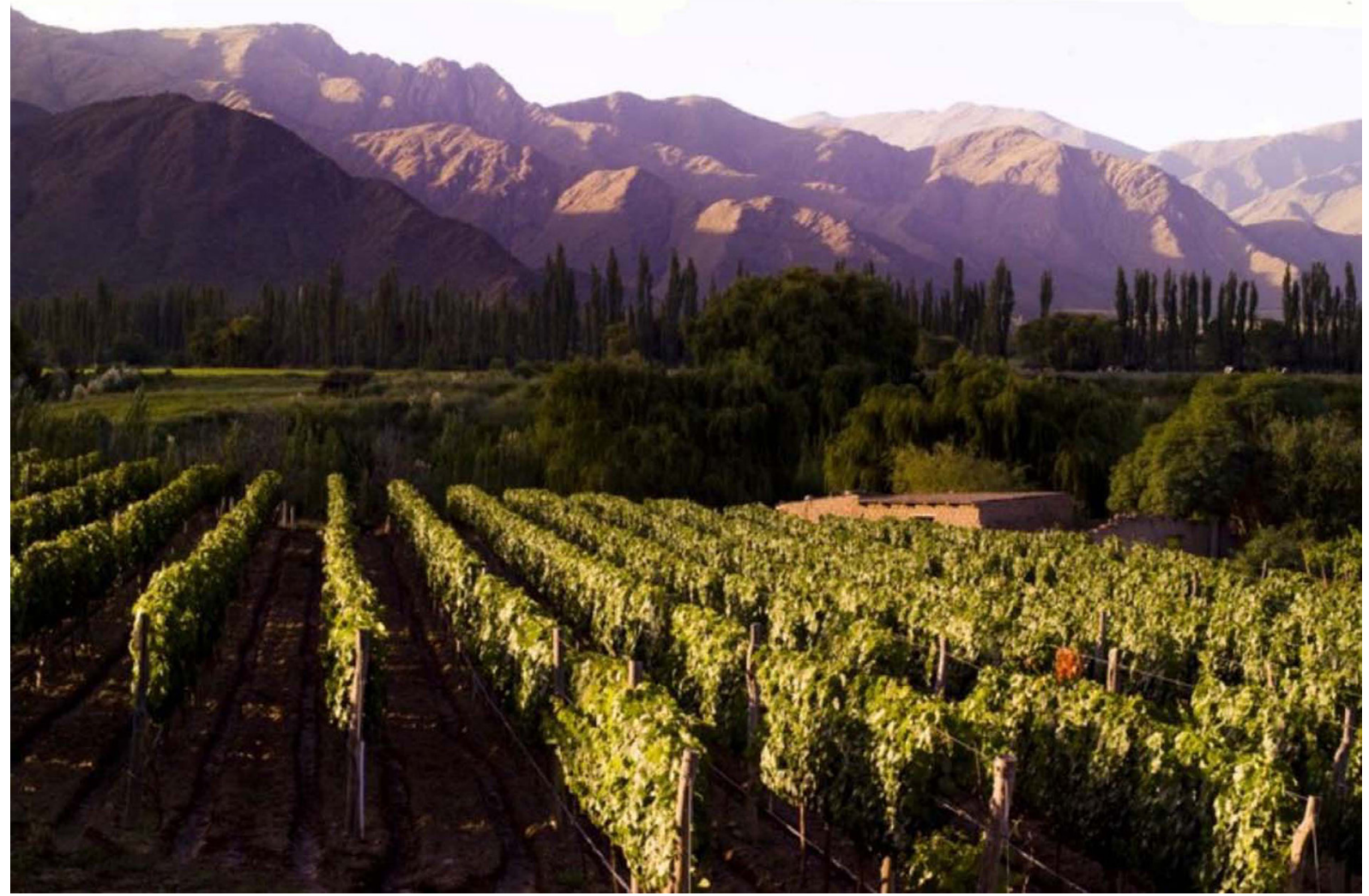

Fonte: Governo de la Provincia de Salta (s.d.)

A composição terrestre, com o término da obra da ponte binacional Brasil/Paraguai, fomentará a conjugação dos destinos turísticos entre esses países (leem-se os quatro países que pertencerão ao Corredor Rodoviário). Possibilidades de "rotas dentro do Corredor", como a conjugação de Salta versus Deserto do Atacama e Antofagasta, em roteiro de 10 dias e 9 noites, de forma terrestre ida e volta desde Campo Grande, e para os que dispuserem de mais dias, conjugar a volta por Assunção, no Paraguai.

Figura 3 - Chá de folha de Coca, usado para amenizar os efeitos da altitude

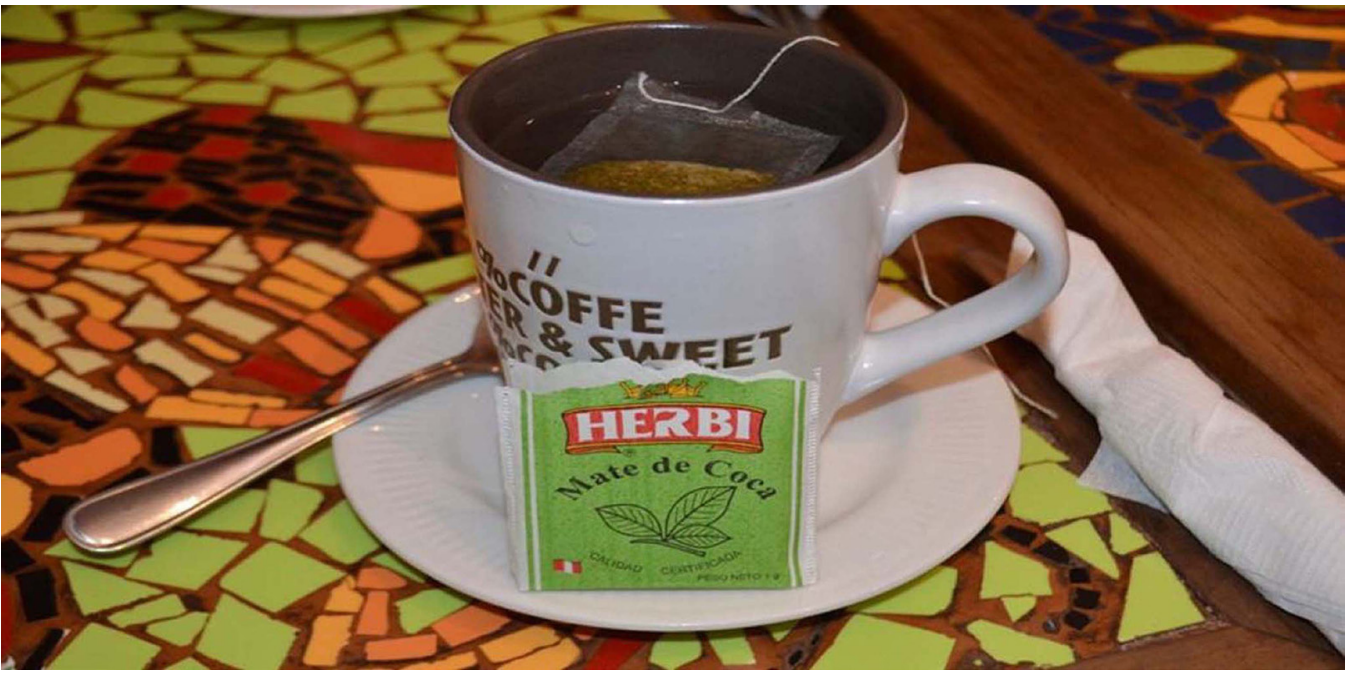

Fonte: G1/MS (2017a) 
As particularidades do Deserto do Atacama, como o Chá de Coca (Figura 3), são típicas de países de altitude. O trecho de Cordilheira, que compreende Argentina e Chile, pelas belezas naturais da vegetação, fomenta o turismo de contemplação. Ocorre mencionar que mesmo antes da construção da ponte, será necessário adequar a infraestrutura nas estradas, com pontos de apoio, postos de combustível, oficinas automotivas, rede hoteleira, a devida sinalização turística e a melhoria nos serviços de comunicação. Os trâmites aduaneiros serão revisados para agilizar a logística do transporte de cargas, um filão que também impulsionará o turismo de negócios, estimando um aumento considerável de veículos à medida que as rodovias estiverem pavimentadas e prontas para o tráfego de todos os tipos de veículos.

Figura 4 - Trecho Chileno de Cordilheira dos Andes

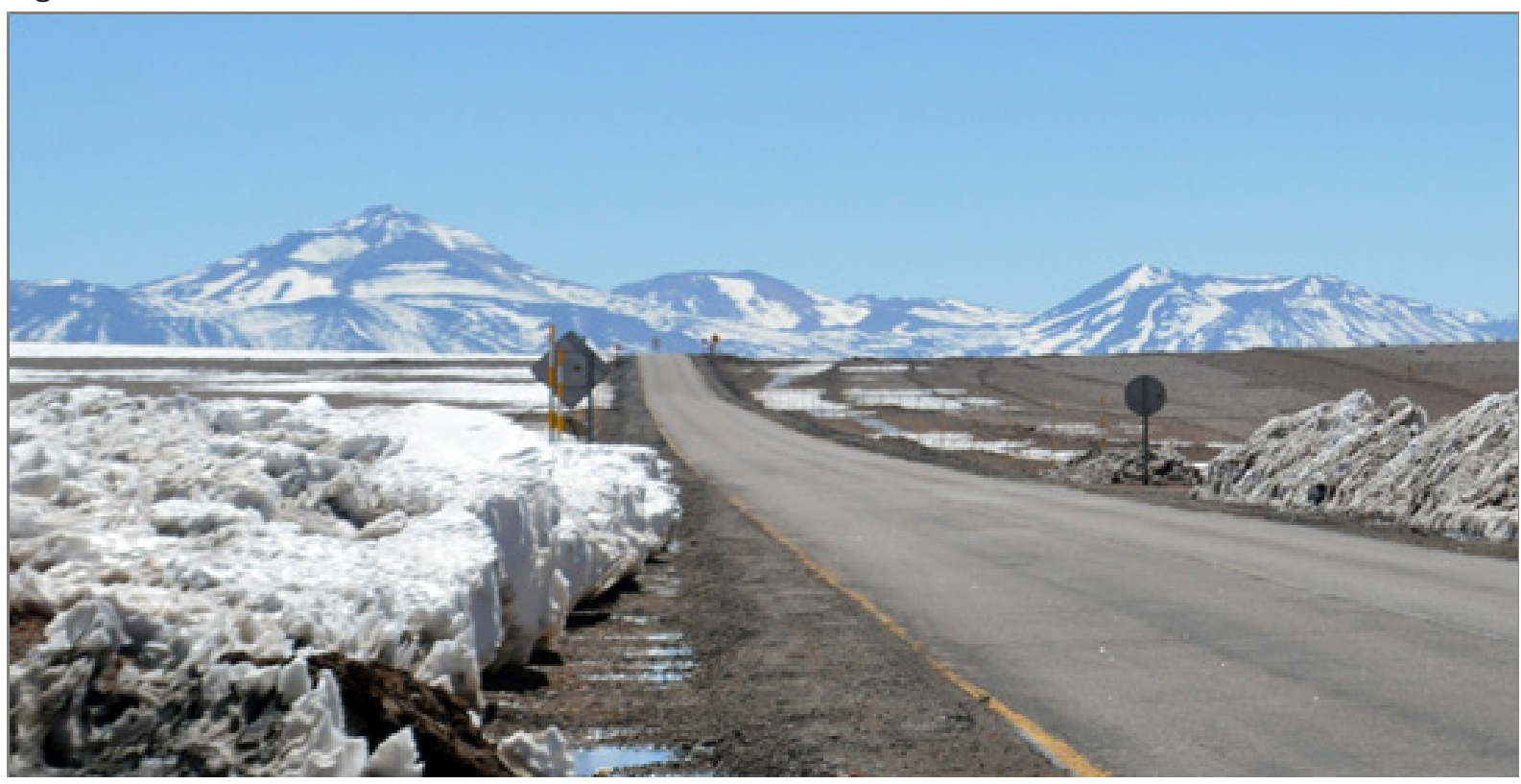

Fonte: G1 MS (VIEGAS, 2017a).

De acordo com os Indicadores de Turismo da Pesquisa "Caracterização e Dimensionamento do Turismo Internacional do Brasil", o Estado de Mato Grosso do Sul, localizado na fronteira com o Paraguai e a Bolívia, nas respectivas cidades de Ponta Porã e Corumbá, está entre as 10 Fronteiras Terrestres que representam cerca de 90\% do Fluxo Internacional Terrestre (FIPE. EMBRATUR/MTUR/2016).

Na figura 5, contextualizam-se os dados revisados de 2013 da Chegada de Turistas Estrangeiros no Brasil por via terrestre e a posição de Mato Grosso do Sul. Se se considerar somente as Chegadas de Turistas Estrangeiros no Brasil pelo Mato Grosso do Sul (dados de 2015), o número de turistas com entrada por via terrestre foi de 55.429, contra apenas 609 por via aérea. 
Figura 5 - Chegadas de Turistas Estrangeiros no Brasil via Terrestre

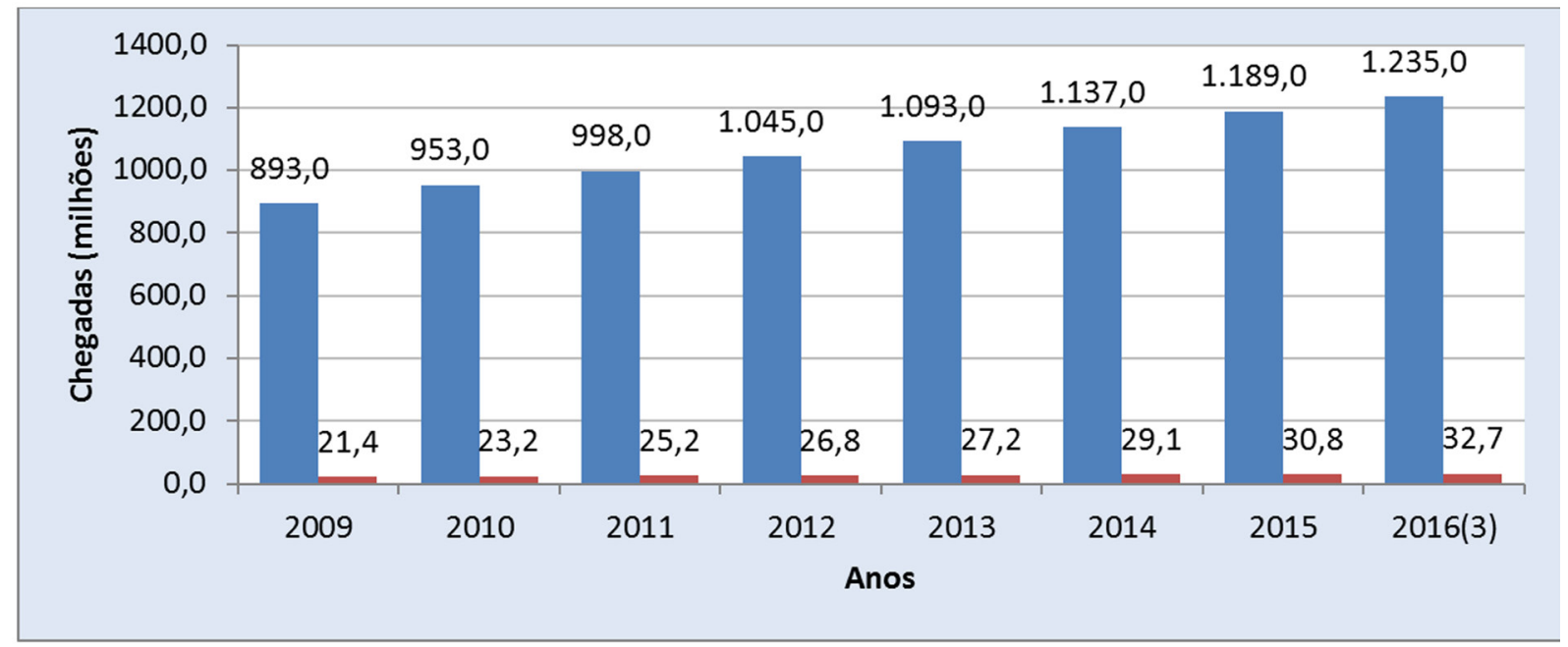

Fonte: Fipe e Embratur/MTur (2016).

A potencialidade do Corredor Rodoviário para o aumento de fluxo de turistas entre os países que serão cortados por ele é uma realidade de médio prazo, estimada para término até meados de 2021. Estatísticas sobre oferta de hotelaria e gastronomia, hospitais, centros de atendimento ao turista (que serão criados a partir da finalização da infraestrutura de estradas) serão instrumentos de novas pesquisas, que serão importantes para a dinâmica da Rota.

\section{CONSIDERAÇÕES FINAIS AINDA QUE PARCIAIS}

A Rota de Integração Latino Americana contribuirá para o desenvolvimento econômico local de Mato Grosso do Sul e dos países que fazem parte de seu Corredor Rodoviário Bioceânico, pela facilidade logística, com a construção da ponte em Ponto Murtinho, ligando Brasil ao Paraguai, e aos demais países do Corredor. Facilitando a logística, emergem as potencialidades para o turismo, pois há uma vontade política do Brasil e do Paraguai para que o processo de sinalização e acordos de transportes de mercadoria e demais trâmites sejam facilitados.

O fortalecimento do turismo ocorrerá de forma gradativa. O nome Rota de Integração Latino-Americana tem um peso e já é uma referência, pois há mais de 10 anos se fala em diminuir as fronteiras entre esses países sul-americanos na forma desse Corredor Rodoviário Bioceânico. Mesmo que no início, contemplasse a passagem pela Bolívia que não ocorreu em razão de questões geopolíticas, e antes mesmo dos acordos firmados entre Brasil e Paraguai, o empresariado (transportadoras e entidades de classe) tem demonstrado interesse nas visitas in loco, e pelo conhecimento de causa e representatividade, tiveram voz no desenvolvimento do projeto.

A comunidade acadêmica, por meio de convênio entre universidades brasileiras e argentinas, merece menção ao projeto de demandar estudos de viabilidade ambiental, social e turístico, com ações coordenadas entre os demais países participantes.

Ademais, é pertinente afirmar que a Rota de Integração Latino-Americana poderá trazer externalidades positivas que vão além do progresso e do dinamismo, mas também de um crescimento atrelado a uma integração cultural, educacional, geradora de renda e que poderá maximizar a qualidade de vida da população do entorno do Corredor Rodoviário Bioceânico. 


\section{REFERÊNCIAS}

EHULETCHE, Ana Belén. Corredor del Sur: la versión ferroviaria del Canal de Panamá. Jornal La Nacion, Buenos Aires, Argentina, 6 jul. 2017. Disponível em: . Acesso em: 23 fev. 2018.

FUNDAÇÃO INSTITUTO DE PESQUISAS ECONÔMICAS (FIPE). Ministério do Turismo. Indicadores turísticos. Pesquisa caracterização e dimensionamento do turismo internacional do Brasil. 2016. Disponível em: http://www.turismo.ms.gov.br/wp-content/uploads/sites/54/2016/09/2016_-indicadores-turisticos_ ms_2015_serie-2007_2014.pdf. Acesso em: 26 fev. 2018.

SALTA (cidade). Governo da Província de Salta. Ruta del vino - Viñedos de altura. [S.d.]. Disponível em: http://turismo.salta.gov.ar/contenidos/14/rutas-tematicas-salta. Acesso em: 25 fev. 2018.

GUNDERMANN, Hans. Inicios de siglo en San Pedro de Atacama: procesos, actores e imaginarios em uma localidad andina. Chungará - Revista de Antropologia Chilena, v. 36, n. 2004, p. 221-39, 2004.

LA NACIÓN. "Corredor granelero" generará impacto positivo para el Norte. Assunção, Paraguai, 1ㅇfev. 2018. Disponível em: http://www.lanacion.com. py/negocios_edicion_impresa/2018/02/01/corredorgranelero-generara-impacto-positivo-para-el-norte. Acesso em: 25 fev. 2018.

KROM, Andrés. Mal trago para la industria del vino: cayeron las ventas 5,7\% en 2017. La Nacion, Buenos Aires, Argentina, 31 jan. 2018. Disponível em: https://www.lanacion.com.ar/economia/mal-trago-parala-industria-del-vino-cayeron-las-ventas-57-en-2017-nid2105240. Acesso em: 23 fev. 2018.

SILBERBERG, Ted. Cultural tourism and business opportunities for museums and heritage sites. Tourism management, Londres, Butterworth-Heinemann, v. 16, n. 5, p. 361-5, 1995.

TAUSSIG, Karen-Sue; HOEYER, Klaus; HELMREICH, Stefan. The Anthropology of potenciality in biomedicine: an introduction to supplement 7. Current Anthropology, v. 54, suplemento 7, p. S3-S14, out. 2013.

VIEGAS, Anderson. Rota de integração deve potencializar turismo entre Brasil, Paraguai, Argentina e Chile. G1 MS. 6 set. 2017a. Disponível em: https://g1.globo.com/mato-grosso-do-sul/rila/noticia/rotade-integracao-deve-potencializar-turismo-entre-brasil-paraguai-argentina-e-chile.ghtml. Acesso em: 25 fev. 2018.

VIEGAS, Anderson. Rodada de Negócios e assinatura de convênios para projetos do corredor marcam Rila na Argentina. G1 MS, 31 ago. 2017b. Disponível em: https://g1.globo.com/mato-grosso-do-sul/rila/noticia/ rodada-de-negocios-e-assinatura-de-convenios-para-projetos-do-corredor-marcam-rila-na-argentina. ghtml. Acesso em: 1 set. 2017.

\section{Sobre os autores:}

Thiago Andrade Asato - Doutorando e Mestre em Desenvolvimento Local pela Universidade Católica Dom Bosco (UCDB), Campo Grande, MS. Bolsista Capes. E-mail: thiago_andrade_asato@hotmail.com, Orcid: http://orcid.org/0000-0001-8865-1518

Michel Constantino - Doutor em Economia pela Universidade de Brasília. Vice-Coordenador do Programa de Pós-Graduação em Desenvolvimento Local da Universidade Católica Dom Bosco - Mestrado e Doutorado, Campo Grande, MS. E-mail: michel@ucdb.br, Orcid: http://orcid.org/0000-0003-2570-0209 
Arlinda Cantero Dorsa: Doutora em Língua Portuguesa pela Pontifícia Universidade Católica (PUC/SP). Coordenadora e Docente do Programa de Mestrado e Doutorado em Desenvolvimento Local Universidade Católica Dom Bosco (UCDB). E-mail: rf5454@ucdb.br, Orcid: http://orcid.org/0000-0002-1120-0273

Milton Augusto Pasquotto Mariani: Pós-Doutorando em Administração e doutor em Geografia (Geografia Humana) pela Universidade de São Paulo. Mestre em História Social pela Pontifícia Universidade Católica de São Paulo, Graduado em Geografia pela Universidade Estadual Paulista Júlio de Mesquita Filho. Docente da Universidade Federal de Mato Grosso do Sul, credenciado nos programas de mestrado em Administração e Estudos Fronteiriços. E-mail: miltmari@terra.com.br, Orcid: http://orcid.org/0000-0001-9485-0150 